\title{
Cholesterol Metabolism in Rat Is Affected by Protocatechuic Acid
}

\author{
Akiko TAMURA ${ }^{1}$, Michihiro Fukushima ${ }^{1, *}$, Ken-ichiro SHImAdA ${ }^{1}$, Kyu-Ho HAN ${ }^{1}$, \\ Mitsuo SEKIKAWA ${ }^{1}$, Shoko WATANABE ${ }^{1}$, Masuo NAKANO ${ }^{1}$, \\ Megumi MATSUMOTO ${ }^{2}$ and Hideyuki CHIJI $^{2}$ \\ ${ }^{1}$ Department of Animal Science, Obihiro University of Agriculture and Veterinary Medicine, \\ Obihiro, Hokkaido 080-8555, Japan \\ ${ }^{2}$ Department of Food Science and Human Nutrition, Faculty of Human Life Science, Fuji Women's University, \\ Hanakawa Minami 4-5, Ishikari, Hokkaido 061-3204, Japan
}

(Received March 17, 2003)

\begin{abstract}
Summary The effects of protocatechuic acid on serum cholesterol and gene expression related to cholesterol metabolism in rats were investigated. Rats were fed a cholesterol-free diet with or without $5 \mathrm{~g}$ protocatechuic acid $/ \mathrm{kg}$ diet for $4 \mathrm{wk}$. There were no significant differences in body weight and food intake among groups through the experimental period. The liver weight in the protocatechuic acid group was significantly lower than that in the control group. The serum total cholesterol, high-density lipoprotein (HDL)-cholesterol and very low-density lipoprotein (VLDL) + intermediate density lipoprotein (IDL) + low-density lipoprotein (LDL)-cholesterol concentrations in the protocatechuic acid group were significantly lower than those in the control group through the feeding period. The hepatic cholesterol concentration in the protocatechuic acid group was significantly higher than in the control group at the end of the 4-wk feeding period. The relative hepatic LDL receptor, apo B, apo E, lecithin-cholesterol acyltransferase (LCAT) and hepatic triglyceride lipase (HTGL) mRNA levels in the protocatechuic acid group were significantly higher than those in the control group. The results of this study suggest the possibility that the increase in the hepatic LDL receptor, apo E, LCAT and HTGL guessed by these mRNAs increase in the protocatechuic acid group lowers the serum total cholesterol level.
\end{abstract}

Key Words protocatechuic acid, serum cholesterol, LDL receptor mRNA, LCAT mRNA, HTGL mRNA

The study of numerous compounds that could be useful as antioxidants, ranging from $\alpha$-tocopherol and $\beta$-carotene to plant antioxidants such as flavones and tannins, has gained increasing interest in the fields of food and medicine. Mori et al. (1) have reported that phenolic compounds, widely distributed as plant constituents, possess chemopreventive activities in tongue, liver, and large bowel carcinogenesis $(2,3)$. For example, protocatechuic acid seems to be a promising candidate for a cancer preventive agent (1). Furthermore, Tseng et al. (4) have isolated and investigated Hibiscus protocatechuic acid from Hibiscus sabdariffa L. For instance, protocatechuic acid showed efficacy against oxidative damage induced by $t$-butyl hydroperoxide in rat primary hepatocytes (5), and an inhibitory effect on tumor promotion in mouse skin (6). Moreover, Zhang et al. (7) have reported that protocatechuic acid is protective to human $\mathrm{LDL}$ from $\mathrm{Cu}^{+2}$-mediated LDL oxidation

\footnotetext{
* Corresponding Author.

E-mail: fukushim@obihiro.ac.jp

Abbreviations: GAPDH, glyceraldehyde-3-phosphate dehydrogenase; GLC, gas-liquid chromatography; HDL, high-density lipoprotein; HTGL, hepatic triglyceride lipase; IDL, intermediate density lipoprotein; LCAT, lecithin-cholesterol acyltransferase; LDL, low-density lipoprotein; VLDL, very lowdensity lipoprotein.
}

and is also effective in preventing the peroxy free radical-induced oxidation of $\alpha$-tocopherol in human LDL.

Although it has been reported that a protocatechuic acid, which may be produced by degradation of cyanidin-3-O- $\beta$-D-glucoside, was present in the small intestine and plasma in rats and the plasma protocatechuic acid and cyanidin-3-O- $\beta$-D-glucoside may contribute to the antioxidant activity of the plasma $(8)$, there have been few reports suggesting the possibility that the plasma cholesterol concentration is reduced by feeding protocatechuic acid. On the other hand, Frank et al. (9) have reported that dietary cyanidin-3-O- $\beta$-D-glucoside and concentrates from black currant and elderberry appear to have little effect on cholesterol levels and the fatty acid pattern in the rat liver. However, Preuss et al. (10) have reported that a combination of chromium polynicotinate and grape seed extract decreases total cholesterol and LDL levels in hypercholesterolemic individuals. We also found that there was a cholesterol-lowering function in protocatechuic acid (unpublished data), but the mechanism previously was not fully understood. In this study, we examined the effects of diets containing $0.5 \%$ protocatechuic acid, which may be produced by degradation of cyanidin-3-O- $\beta$-D-glucoside, on serum lipids, liver lipids and hepatic mRNAs. 


\section{MATERIALS AND METHODS}

Animals and diets. Males F344/DuCrj rats (8 wkold) were purchased from Charles River Japan, Inc. (Yokohama, Japan). All animals were housed individually in cages on a $12 \mathrm{~h}$ light-dark cycle. Temperature and humidity were controlled at $23 \pm 1{ }^{\circ} \mathrm{C}$ and $60 \pm 5 \%$, respectively. The rats were divided into two groups of five animals each by randomization. There were no significant differences in body weights and serum total cholesterol concentrations between groups at the start of the experimental period. The composition of each diet is shown in Table 1. The experimental group was fed a diet that contained $5 \mathrm{~g}$ protocatechuic acid/ $\mathrm{kg}$ diet for $4 \mathrm{wk}$. The control group consisted of rats fed a basal diet following AIN 76 (11). The rats were allowed free access to experimental diets and water for $4 \mathrm{wk}$. Body weight and feed consumption were recorded weekly and daily, respectively. This experimental design was approved by the Animal Experiment Committee of Obihiro University of Agriculture and Veterinary Medicine. All animal procedures described conformed to standard principles in Guide for the Care and Use of Laboratory Animals (12)

Analytical procedures. Blood samples $(1 \mathrm{~mL})$ were collected between 0800 and $1000 \mathrm{~h}$ from the jugular veins of fasting rats. The samples were taken into tubes without an anticoagulant. After the samples stood at room temperature for $2 \mathrm{~h}$, serum was prepared by centrifugation at $1,500 \times g$ for $20 \mathrm{~min}$. At the end of the experimental period of $4 \mathrm{wk}$, all fecal excretion during $2 \mathrm{~d}$ was collected. Fecal dry weights did not significantly differ among groups. The rats were sacrificed by ether inhalation, and the liver and cecum quickly removed, washed with cold saline $(9 \mathrm{~g} \mathrm{NaCl} / \mathrm{L})$, blotted dry on filter paper, and weighed before freezing for storage.

Chemical analysis. Total cholesterol and HDL-cholesterol concentrations in the serum were determined enzymatically using commercially available reagent kits (assay kits for the TDX system; Abbott Laboratory Co., Irving, TX, USA). The very low-density lipoprotein (VLDL) + intermediate density lipoprotein (IDL) + lowdensity lipoprotein (LDL)-cholesterol concentration was calculated as follows: VLDL+IDL+LDL-cholesterol=

Table 1. Composition of the experimental diet.

\begin{tabular}{lcc}
\hline & \multicolumn{2}{c}{ Diet } \\
\cline { 2 - 3 } & Control & Protocatechuic acid \\
\hline & \multicolumn{2}{c}{$(\mathrm{g} / 100 \mathrm{~g})$} \\
Casein & 25 & 25 \\
Corn oil & 5 & 5 \\
Mineral mixture & 1.5 & 3.5 \\
Vitamin mixture & 5 & 1 \\
Cellulose powder & 0.2 & 5 \\
Choline chloride & - & 0.2 \\
Protocatechuic acid & to 100 & 100 \\
Sucrose & & 0.5 \\
\hline
\end{tabular}

total cholesterol-HDL-cholesterol.

Total lipid was extracted from liver and feces by a mixture of chloroform/methanol (2:1, v/v) (13). The neutral sterol in each total lipid obtained by saponification was acetylated (14) and analyzed by gas-liquid chromatography (GLC) using a Shimadzu 14A chromatograph (Shimadzu, Kyoto, Japan) with a DB17 capillary column (0.25 mm $\times 30 \mathrm{~m}$; J\&W Scientific, Folsom, CA, USA) with nitrogen as the carrier gas. Acidic sterols in feces were measured by GLC following the method of Grundy et al. (15).

RNA isolation, RT-PCR and Southern blot analysis. Total RNA was isolated by the acid guanidium-phenolcholoroform method, using Isogen (Nippon Gene, Tokyo, Japan) from the liver (16). mRNA encoding apo $\mathrm{B}$, apo E, LDL receptor, scavenger receptor class B type I (SR-BI), lecithin-cholesterol acyltransferase (LCAT), hepatic triglyceride lipase (HTGL) or glyceraldehyde-3phosphate dehydrogenase (GAPDH, used as an invariant control) was analyzed by semi-quantitative RT-PCR and subsequent Southern hybridization of the PCR products with each inner oligonucleotide probe. Total RNA samples were treated with DNase RQ1 (Promega, WI, USA) to remove genomic DNA and subjected to RTPCR using Moloney murine leukemia virus reverse transcriptase (GIBCO, Gaithersburg, MD, USA) and EXTaq polymerase (Takara, Tokyo, Japan) with apo B primers of oligonucleotides (upstream primer, 5'-GAAAGCATGCTGAAAACAACC-3'; downstream primer, 5'AGGCCTGACTCGTGGAAGAA-3'), apo E primers of oligonucleotides (upstream primer, 5' - GCTCTGTGGGCCCTGCTGTTG-3'; downstream primer, 5'-GGTTGGCTGTGCGCTGACGAC-3'), LDL receptor primers of oligonucleotides (upstream primer, 5'-ATTTTGGAGGATGAGAAGCAG-3'; downstream primer, 5'-CAGGGCGGGGAGGTGTGAGAA-3'), SR-BI primers of oligonucleotides (upstream primer, 5'-GTAGGGCCCAGAAGACACCAC-3'; downstream primer, 5'-CCTGCCACCGCTGCCACTTAC3'), LCAT primers of oligonucleotides (upstream primer, 5'-TGGGTATGTGCGGGATGAGAC-3'; downstream primer, 5'-TGGCGGTTGGGGACTTAGGAG-3'), HTGL primers of oligonucleotides (upstream primer, 5'-GCGCCTTTCTCCAGATGATGC-3'; downstream primer, 5'-ACTGCGCTGTTTTCCCACTTG-3'), and GAPDH primers of oligonucleotides (upstream primer, 5'-GCCATCAACGACCCCTTCATT-3'; downstream primer, 5'-CGCCTGCTTCACCACCTTCTT-3'). The reaction mixtures for PCR contained 25 pmol of each primer, $1.25 \mathrm{U}$ EX-Taq polymerase, $1 \times$ PCR buffer (Takara), and $200 \mathrm{mM}$ dNTPs in a $50 \mu \mathrm{L}$ reaction volume. The expected sizes of DNA fragments amplified with these primers were $725 \mathrm{bp}$ for apo B, $607 \mathrm{bp}$ for apo E, $931 \mathrm{bp}$ for the LDL receptor, 539 bp for SR-BI, 835 bp for LCAT, 656 bp for HTGL and 702 bp for GAPDH. Temperature cycling was as follows: first cycle, denaturation at $94^{\circ} \mathrm{C}$ for $3 \mathrm{~min}$, annealing at $60^{\circ} \mathrm{C}$ for $1 \mathrm{~min}$, and extension at $72^{\circ} \mathrm{C}$ for $2 \mathrm{~min}$. Subsequent cycles were denaturation at $94^{\circ} \mathrm{C}$ for $1 \mathrm{~min}$, annealing at $60^{\circ} \mathrm{C}$ for $1 \mathrm{~min}$, and extension at $72^{\circ} \mathrm{C}$ for $2 \mathrm{~min}$. The thermal cycling was completed by terminal extension at $72^{\circ} \mathrm{C}$ for $10 \mathrm{~min}$. In total, 15 cycles were 
performed for apo E amplifications, 20 cycles for HTGL, 25 cycles for the apo B, the LDL receptor, the SR-BI and the LCAT and 20 cycles for GAPDH. Amplification products were electrophoresed on $2 \%$ agarose gel, and transferred to nylon membranes (Biodyne B, Pall BioSupport, East Hills, NY). Blots were hybridized with an apo B probe of a 54-base oligonucleotide (5'-TCCTTGCTTACCAAAAAGAGCTTCCAGTGTTGGCTCAAAGCCCTTTCCTTCTAA-3'), apo E probe of a 54-base oligonucleotide (5'-CCAGGGTTGGTCGCTTTGCCCTGGGAGCTGATCTGTCACCTCCAGCTCTCCCTC-3'), LDL receptor probe of a 54-base oligonucleotide (5'-GTGAACTTGGGTGAGTGGGCACTGATCTGAGGGGCAGGCAGGCACATGTACTGG-3'), LCAT probe of a 52-base oligonucleotide (5'ATCTGTCCCATTCATGCGGAGCAAGTGTACACCCTGTGACTGGCGGCCCTGC-3'), HTGL probe of a 54-base oligonucleotide (5'-GAACTGGTAATGATAAACTTTAAAGGGGGACTGGGCTCGGGTGATGAGGAAGAG-3'), and GAPDH probe of a 54-base oligonucleotide (5'-TGATGACCAGCTTCCCATTCTCAGCCTTGACTGTGCCGTTGAACTTGCCGTGGG-3'). The probe was 3'-tailing labeled with digoxigenin, using a DIG oligonucleotide tailing kit (Boehringer Mannheim, Germany). Prehybridization, hybridization and detection were carried out with a DIG luminescent detection kit (Boehringer Mannheim) as recommended by the manufacturer. The relative quantity of mRNA was estimated by densitometry scanning with X-ray film.

Statistical analysis. Data are presented as means and standard deviations. The mean and standard deviation for serum total cholesterol, HDL-cholesterol, and $\mathrm{VLDL}+\mathrm{IDL}+\mathrm{LDL}$-cholesterol for each time point were calculated. The significance of differences among treatment groups was determined by Student's $t$ test.

\section{RESULTS}

\section{Food intake, rat growth, and liver weight}

The results are summarized in Table 2. There were no significant differences in body weight and food intake among groups throughout the experimental period. The liver weight in the protocatechuic acid group was significantly lower than that in the control group.

Table 2. Body weight gain, food intake and liver weight of rats fed protocatechuic acid for $4 \mathrm{wk} .^{1}$

\begin{tabular}{lcc}
\hline & \multicolumn{2}{c}{ Diet } \\
\cline { 2 - 3 } & Control & $\begin{array}{c}\text { Protocatechuic } \\
\text { acid }\end{array}$ \\
\hline Body initial weight $(\mathrm{g})$ & $150 \pm 3$ & $150 \pm 2$ \\
Body final weight $(\mathrm{g})$ & $224 \pm 7$ & $222 \pm 9$ \\
Body weight gain $(\mathrm{g} / 4 \mathrm{wk})$ & $72.2 \pm 9.7$ & $72.2 \pm 9.7$ \\
Total food intake $(\mathrm{g} / 4 \mathrm{wk})$ & $395 \pm 14$ & $395 \pm 14$ \\
Liver weight & $4.5 \pm 0.1$ & $3.9 \pm 0.4^{*}$ \\
$\quad$ (wet g/100 g body weight) & & \\
\hline
\end{tabular}

${ }^{1}$ Values are means \pm SD for five rats. Mean values were significantly different from the control group: ${ }^{*} p<0.05$.
Table 3. Serum cholesterol concentrations in rats fed protocatechuic acid for $4 \mathrm{wk}^{1}$

\begin{tabular}{ccc}
\hline & \multicolumn{3}{c}{ Diet } \\
\cline { 2 - 3 } Control & Protocatechuic acid \\
\hline \multicolumn{3}{c}{ Total cholesterol $(\mathrm{mmol} / \mathrm{L})$} \\
$0 \mathrm{wk}$ & $1.70 \pm 0.08$ & $1.61 \pm 0.11$ \\
$1 \mathrm{wk}$ & $2.98 \pm 0.48$ & $2.43 \pm 0.27^{*}$ \\
$2 \mathrm{wk}$ & $3.05 \pm 0.28$ & $2.33 \pm 0.23^{*}$ \\
$3 \mathrm{wk}$ & $2.90 \pm 0.18$ & $2.46 \pm 0.30^{*}$ \\
$4 \mathrm{wk}$ & $2.92 \pm 0.35$ & $2.30 \pm 0.14^{*}$ \\
HDL-cholesterol $(\mathrm{mmol} / \mathrm{L})$ & \\
$0 \mathrm{wk}$ & $1.18 \pm 0.09$ & $1.16 \pm 0.08$ \\
$1 \mathrm{wk}$ & $2.00 \pm 0.26$ & $1.62 \pm 0.20^{*}$ \\
$2 \mathrm{wk}$ & $2.02 \pm 0.16$ & $1.56 \pm 0.12^{*}$ \\
$3 \mathrm{wk}$ & $1.94 \pm 0.22$ & $1.65 \pm 0.13^{*}$ \\
$4 \mathrm{wk}$ & $2.04 \pm 0.22$ & $1.56 \pm 0.12^{*}$ \\
VLDL $+\mathrm{IDL}+\mathrm{LDL}-\mathrm{cholesterol^{2 }}(\mathrm{mmol} / \mathrm{L})$ \\
$0 \mathrm{wk}$ & $0.52 \pm 0.06$ & $0.45 \pm 0.04$ \\
$1 \mathrm{wk}$ & $0.98 \pm 0.25$ & $0.81 \pm 0.12^{*}$ \\
$2 \mathrm{wk}$ & $1.03 \pm 0.18$ & $0.76 \pm 0.14^{*}$ \\
$3 \mathrm{wk}$ & $0.95 \pm 0.12$ & $0.81 \pm 0.17^{*}$ \\
$4 \mathrm{wk}$ & $0.88 \pm 0.14$ & $0.74 \pm 0.04^{*}$ \\
& & \\
\hline
\end{tabular}

${ }^{1}$ Values are means \pm SD for five rats. Mean values were significantly different from the control group: ${ }^{*} p<0.05$.

${ }^{2} \mathrm{VLDL}+\mathrm{IDL}+\mathrm{LDL}-\mathrm{cholesterol}=($ Total cholesterol $)-(\mathrm{HDL}-$ cholesterol).

Table 4. Liver cholesterol and fecal bile acid concentrations in rats fed protocatechuic acid for $4 \mathrm{wk} .^{1}$

\begin{tabular}{ccc}
\hline & \multicolumn{2}{c}{ Diet } \\
\cline { 2 - 3 } & Control & $\begin{array}{c}\text { Protocatechuic } \\
\text { acid }\end{array}$ \\
\hline Liver $(\mu \mathrm{mol} / \mathrm{g}$ wet liver $)$ & & \\
Cholesterol & $0.77 \pm 0.42$ & $1.90 \pm 0.56^{*}$ \\
Feces $(\mu \mathrm{mol} / \mathrm{g}$ dry feces $)$ & $<0.01$ & $<0.01$ \\
Cholic acid & $<0.01$ & $<0.01$ \\
Chenodeoxycholic acid & $0.02 \pm 0.01$ & $0.01 \pm 0.01$ \\
Deoxycholic acid & $0.04 \pm 0.01$ & $0.04 \pm 0.02$ \\
Lithocholic acid & $0.06 \pm 0.02$ & $0.05 \pm 0.03$ \\
Total bile acid &
\end{tabular}

\footnotetext{
${ }^{1}$ Values are means \pm SD for five rats. Mean values were
} significantly different from the control group: ${ }^{*} p<0.05$.

\section{Tissue lipid concentration}

Table 3 shows the serum total cholesterol, VLDL+ IDL + LDL-cholesterol and HDL-cholesterol concentrations in rats. The serum total cholesterol, VLDL+ IDL+LDL-cholesterol and HDL-cholesterol concentrations in the protocatechuic acid group were significantly lower than those in the control group throughout the feeding period.

Table 4 shows the effects of the protocatechuic acid on the liver cholesterol and fecal bile acid concentrations in rats at the end of the experimental period. The liver cholesterol concentration in the protocatechuic 

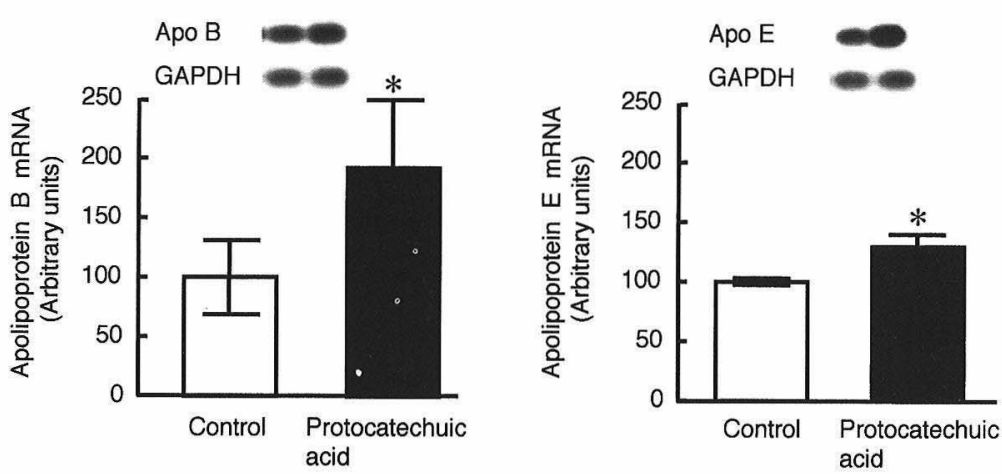

Fig. 1. Apo B and apo E mRNA concentrations in rats fed protocatechuic acid for 4 wk. Each value represents the mean $\pm \mathrm{SD}, n=5$. Mean values were significantly different from the control group: ${ }^{*} p<0.05$. The values of apo $\mathrm{B}$ and apo $\mathrm{E}$ mRNAs were normalized to the value of GAPDH, and values for the rats fed the protocatechuic acid diet are expressed relative to the average value for rats fed the control diet, which was set to 100. Top panel illustrates the representative Southern hybridization of PCR amplified apo B and apo E cDNAs of hepatic RNAs.
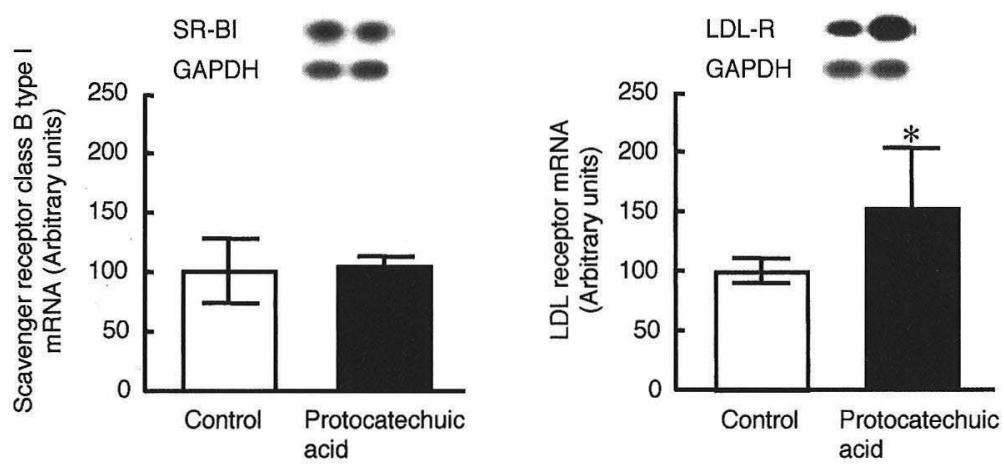

Fig. 2. Scavenger receptor class B type I (SR-BI) and LDL receptor mRNA concentrations in rats fed protocatechuic acid for 4 wk. Each value represents the mean $\pm S D, n=5$. Mean values were significantly different from the control group: ${ }^{*} p<0.05$. The values of SR-BI and LDL receptor mRNAs were normalized to the value of GAPDH, and values for the rats fed the protocatechuic acid diet are expressed relative to the average value for rats fed the control diet, which was set to 100. Top panel illustrates the representative Southern hybridization of PCR amplified SR-BI and LDL receptor cDNAs of hepatic RNAs.
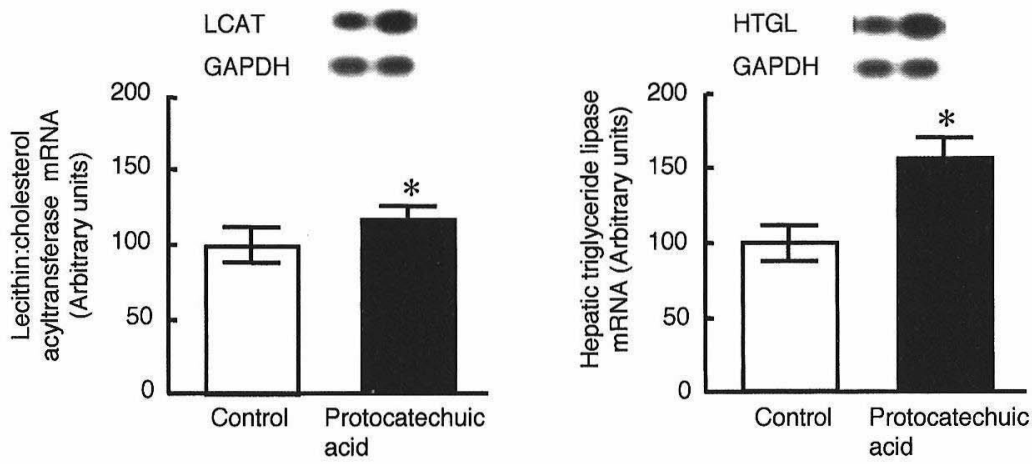

Fig. 3. Lecithin: cholesterol acyltransferase (LCAT) and hepatic triglyceride lipase (HTGL) mRNA concentrations in rats fed protocatechuic acid for $4 \mathrm{wk}$. Each value represents the mean $\pm \mathrm{SD}, n=5$. Mean values were significantly different from the control group: ${ }^{*} p<0.05$. The values of LCAT and HTGL mRNAs were normalized to the value of GAPDH, and values for the rats fed the protocatechuic acid diet are expressed relative to the average value for rats fed the control diet, which was set to 100. Top panel illustrates the representative Southern hybridization of PCR amplified LCAT and HTGL cDNAs of hepatic RNAs.

acid group was significantly higher than that in the control group. There was no significant difference in bile acid concentration among groups throughout the experimental period.

Hepatic $m R N A$

The relative quantities of mRNAs were determined by the Southern hybridization of PCR amplified apo B
cDNA, apo E cDNA, LDL receptor cDNA, SRBI cDNA, LCAT CDNA and HTGL cDNA (Figs. 1-3) in the rat liver. The values of apo B, apo E, LDL receptor, SRBI, LCAT and HTGL mRNAs were normalized to the value of GAPDH. The values of the protocatechuic acid-fed rats were expressed relative to the average values of the control group, which were normalized to 100 . The relative 
quantities of hepatic apo B, apo E, LDL receptor, LCAT and HTGL mRNAs in the protocatechuic acid group were significantly higher than in the control group $(p<0.05)$. However, there was no significant difference in the hepatic SR-BI mRNA level among groups.

\section{DISCUSSION}

Though we have no data regarding the absorption of protocatechuic acid in the small intestine, it may be possible that protocatechuic acid was absorbed from the small intestine of rats, because Tsuda et al. (8) have reported that protocatechuic acid, which may be produced by degradation of cyanidin 3-O- $\beta$-D-glucoside, was present in the small intestine and plasma in rats. On the other hand, Frank et al. (9) have reported that dietary cyanidin-3-O-glucoside and concentrates from black currant and elderberry appear to have little effect on cholesterol levels and the fatty acid pattern in the rat liver. It has also been reported that $0.01 \%$ protocatechuic acid and $0.15 \%$ acylanthocyanin protect against $t$-BHP- and paraquat-induced hepatotoxicity by its antioxidant $(17,18)$. In this study, the dose of $0.5 \%$ protocatechuic acid is approximately $70 \mathrm{mg} / \mathrm{d}$, and thus is equivalent to a $60 \mathrm{~kg}$ person consuming approximately $21 \mathrm{~g}$ of protocatechuic acid. Though the value is an overdose and 3-fold dose of acylanthocyanin (18), we examined the beneficial effects of protocatechuic acid, which may be produced by degradation of cyanidin 3$O-\beta$-D-glucoside, on serum cholesterol and hepatic mRNA levels in rats in the present study.

Matsumoto et al. (19) have reported that liver weight increased significantly with a $15 \%$ lard and $1 \%$ cholesterol diet as compared to a basal diet, and decreased with the addition of $1 \%$ black tea polyphenols, which suppressed the increase of triglyceride levels in the liver caused by a high-fat diet. Our data also show that liver weight decreased significantly with a $0.5 \%$ protocatechuic acid diet as compared to the basal diet. It may be that protocatechuic acid suppresses the increase of TG levels under a low-fat diet condition. The serum total cholesterol concentration in the protocatechuic acid group was significantly lower than in the control group. The factor lowering the cholesterol concentrations in the protocatechuic acid group was the lowering of HDLand VLDL+IDL+LDL-cholesterol concentrations. It has been suggested that sugarbeet fiber reduces ileal concentrations of apo A-I and apo A-IV mRNA in rats (20). In the present experiment, protocatechuic acid increased the hepatic concentration of apo B mRNA in rats. However, protocatechuic acid also increased the hepatic concentration of apo E mRNA in rats. A pivotal role of apo E in plasma is to mediate the hepatic and extrahepatic uptake of plasma lipoproteins by binding with high affinity to all members of the LDL-receptor family, including the LDL-receptor, the LDL-receptorrelated protein, the VLDL receptor, GP330/megalin, and ApoER-2 (21). In this experiment, the LDL receptor mRNA level also increased in the protocatechuic acid group. The results suggested that protocatechuic acid increased hepatic uptake of the IDL + LDL and HDL into the LDL receptor and apo E receptor, because Goldstein et al. (22) reported that HDL is the lipoprotein that removes cholesterol from extrahepatic cells and the cholesterol is delivered to IDL through the action of plasma LCAT. The surfaces of IDL particles from VLDL and HDL contain apo E and apo B-100, and the hepatic LDL receptor has a much higher affinity for lipoproteins containing apo $\mathrm{E}$ than for those containing apo B-100 (23). The LCAT mRNA level also increased in the protocatechuic acid group as compared with the control group in this experiment. This suggested that the lowering of the HDL-cholesterol concentration in the protocatechuic acid group could be explained by the increasing LCAT mRNA level. This high affinity for apo E allows hepatic LDL receptors to mediate the extremely rapid clearance of apo E-containing IDL from the circulation before the particles can be converted to LDL (24).

In this study, the HTGL mRNA level also increased in the protocatechuic acid group as compared with the control group. HTGL catalyzes the hydrolysis of triglycerides and causes the conversion of triglyceride-rich chylomicrons and VLDL particles into cholesterol-rich remnant particles (25). Medh et al. (26) demonstrated that hepatic HTGL enhances VLDL degradation in cultured cells by an LDL receptor-mediated mechanism. It has also been reported that familial HTGL deficiency results in typical type III hyperlipoproteinemia with impaired clearance of chylomicron remnants $(27)$. It may also be that the serum VLDL+IDL+LDL-cholesterol concentration was reduced in the protocatechuic acid group due to the increasing HTGL mRNA level in the present study.

In this study, the reasons for the increases in the relative hepatic LDL receptor, apo B, apo E, LCAT and HTGL mRNA levels in the protocatechuic acid group were unclear. However, Pal et al. have reported (28) that polyphenolics in red wine increased HMG-CoA reductase and LDL receptor mRNA levels in human HepG2 cell. Thus, it is suggested that it was the polyphenolics in the red wine, and not the alcohol component, that was affecting these major pathways in lipoprotein metabolism (28). Protocatechuic acid may upregulate the relative hepatic LDL receptor, apo B, apo E, LCAT and HTGL mRNA levels in the present study.

The factor increasing the hepatic cholesterol concentration in the protocatechuic acid group might also have increased hepatic uptake of the IDL+LDL and HDL into the LDL receptor family in this experiment, because, there was no significant difference in the fecal total bile acid concentrations among groups.

In conclusion, the effects of protocatechuic acid were most clearly seen when compared with rats fed the control diet. Protocatechuic acid elevated hepatic LDL receptor, apo E, LCAT and HTGL mRNA levels, reduced the VLDL+IDL+LDL- and HDL-cholesterol concentrations and lowered the serum total cholesterol concentration in the protocatechuic acid group.

\section{Notice of grant support}

This research was supported partially by a grant 
from the 21st Century COE Program (A-1), Ministry of Education, Culture, Sports, Science, and Technology, Japan and by the Research and Development Program for New Bio-industry of the Bio-oriented Technology Research Advancement Institution.

\section{REFERENCES}

1) Mori H, Tanaka T, Sugie S, Yoshimi N, Kawamori $T$, Hirose Y, Ohnishi M. 1997. Chemoprevention by naturally occurring and synthetic agents in oral, liver, and large bowel carcinogenesis. J Cell Biochem Suppl 27: 3541.

2) Kawamori T, Tanaka T, Kojima T, Suzui M, Ohnishi M, Mori H. 1994. Suppression of azoxymethane-induced rat colon aberrant crypt foci by dietary protocatechuic acid. Jpn J Cancer Res 85: 686-691.

3) Hirose Y, Tanaka T, Kawamori T, Ohnishi M, Makita H, Mori H, Satoh K, Hara A. 1995. Chemoprevention of urinary bladder carcinogenesis by the natural phenolic compound protocatechuic acid in rats. Carcinogenesis 16: 2337-2342.

4) Tseng TH, Tsheng YM, Lee YJ. 2001. Cytotoxicity effects of di- and tri-hydroxybenzaldehydes as a chemopreventive potential agent on tumor cells. Toxicology 161: 179-187.

5) Tseng TH, Wang CJ, Kao ES, Chu HY. 1996. Hibiscus protocatechuic acid protects against oxidative damage induced by $t$-butylhydroperoxide in rat primary hepatocytes. Chem Biol Interact 101: 137-148.

6) Tseng TH, Hsu JD, Lo MH, Chu HY, Chu FP, Huang CL, Wang CJ. 1998. Inhibitory effect of hibiscus protocatechuic acid on tumor promotion in mouse skin. Cancer Lett 126: 199-207.

7) Zhang Z, Chang Q, Huang Y, Walter KKH, Chen ZY. 2001. Characterization of antioxidants present in hawthorn fruits. J Nutr Biochem 12: 144-152.

8) Tsuda T, Horio F, Osawa T. 1999. Absorption and metabolism of cyanidin 3-O- $\beta$-D-glucoside in rats. FEBS Lett 449: 179-182.

9) Frank J, Kamal-Eldin A, Lundh T, Maatta K, Torronen R, Vessby B. 2002. Effects of dietary anthocyanins on tocopherols and lipids in rats. J Agric Food Chem 50: $7226-$ 7230.

10) Preuss HG, Wallerstedt D, Talpur N, Tutuncuoglu SO, Echard B, Myers A, Bui M, Bagchi D. 2000. Effects of niacin-bound chromium and grape seed proanthocyanidin extract on the lipid profile of hypercholesterolemic subjects: a pilot study. J Med 31: 227-246.

11) American Institute of Nutrition. 1977. Report of the American Institute of Nutrition ad hoc committee on standards for nutritional studies. I Nutr 107: 13401348 .

12) National Research Council. 1985. Guide for the Care and Use of Laboratory Animals. Publication no. 85-23 (rev.), National Institute of Health, Bethesda, MD.

13) Folch J, Lees M, Sloane-Stanley JH. 1957. A simple method for the isolation and purification of total lipids from animal tissues. J Biol Chem 226: 497-509.
14) Matsubara Y, Sawabe A, Iizuka Y. 1990. Structures of new linoroid glycosides in lemon (Citrus limon Burm. f.) peelings. Agric Biol Chem 54: 1143-1148.

15) Grundy SM, Ahrens EH Jr, Miettinen TA. 1965. Quantitative isolation and gas-liquid chromatographic analysis of total fecal bile acids. J Lipid Res 6: 397-410.

16) Chomczynski P, Sacchi N. 1987. Single-step method of RNA isolation by acid guanidium thiocyanate-phenolchloroform extraction. Anal Biochem 162: 156-159.

17) Liu CL, Wang JM, Chu CY, Cheng MT, Tseng TH. 2002. In vivo protective effect of protocatechuic acid on tertbutyl hydroperoxide-induced rat hepatotoxicity. Food Chem Toxicol 40: 635-641.

18) Igarashi K, Satoh M, Terahara N, Tsuda T, Tsushida T, Kajimoto O. 2000. Anthocyanin of biological function. In: Anthocyanins-Food Color with Health Benefits (Ohba R, Igarashi K, Tsukui A, eds), p 151-163. Kenpakusha Co, Ltd, Tokyo.

19) Matsumoto N, Okushio K, Hara Y. 1998. Effect of black tea polyphenols on plasma lipids in cholesterol-fed rats. J Nutr Sci Vitaminol 44: 337-342.

20) Sonoyama K, Nishikawa H, Kiriyama S, Niki R. 1995. Apolipoprotein mRNA in liver and intestine of rats is affected by dietary beet fiber or cholestyramine. J Nutr 125: 13-19.

21) Nimpf J, Schneider WJ. 2000. From cholesterol transport to signal transduction: low-density lipoprotein receptor, very low-density lipoprotein receptor, and apolipoprotein E receptor-2. Biochim Biophys Acta 1529: 287-298.

22) Goldstein JL, Kita T, Brown MS. 1983. Defective lipoprotein receptors and atherosclerosis. N Engl J Med 309 : 288-296.

23) Brown MS, Kovanen PT, Goldstein JL. 1981. Regulation of plasma cholesterol by lipoprotein receptors. Science 212: 628-635.

24) Kita T, Brown MS, Bilheimer DW, Goldstein JL. 1982. Delayed clearance of very low-density and intermediate density lipoproteins with enhanced conversion to lowdensity lipoprotein in WHHL rabbits. Proc Natl Acad Sci USA 79: 5693-5697.

25) Olivecrona G, Olivecrona T. 1995. Triglyceride lipases and atherosclerosis. Curr Opin Lipidol 6: 291-305.

26) Medh DJ, Bowen SL, Fry GL, Ruben S, Hill J, Wong H, Chappell DA. 1999. Hepatic triglyceride lipase promotes low-density lipoprotein receptor-mediated catabolism of very low-density lipoproteins in vitro. J Lipid Res 40: 1263-1275.

27) Breckenridge WC, Little JA, Alaupovic P, Wang CS, Kuksis A, Kakis G, Lindgren F, Gardiner G. 1982. Lipoprotein abnormalities associated with a familial deficiency of hepatic lipase. Atherosclerosis 45: 161-179.

28) Pal S, Ho N, Santos C, Dubois P, Mamo J, Croft K, Allister E. 2003. Red wine polyphenolics increase LDL receptor expression and activity and suppress the secretion of Apo B 100 from human HepG2 cells. J Nutr 133: 700706. 